\title{
It's Time for a New Journal!
}

Author

Affiliation

\section{H. K. Biesalski}

Institute of Biological Chemistry and Nutrition, University of Stuttgart, Germany
Bibliography

DOI http://dx.doi.org/

10.1055/s-0033-1334960

Published online:

February 27, 2013

Metab Nutr Oncol 2013;

1: e1 $\odot$ Georg Thieme Verlag

KG Stuttgart · New York

elSSN 2194-735X

Correspondence

Prof. Dr. med. Hans Konrad

\section{Biesalski}

Institut für Biologische Chemie

und Ernährungswissenschaft

Emil-Wolff-Straße 12

70599 Stuttgart

biesal@uni-hohenheim.de
Dear Colleague,

Yet another oncology journal, you may be asking yourself. There's plenty already. What might be the raison d'être behind Metabolism and Nutrition in Oncology? Does it promise something which other journals don't already deliver? It does indeed.

A connection has long been drawn between nutrition and cancer, with regards to both prevention and therapy, with often conflicting conclusions being drawn. When it comes to avoiding and treating cancer, we have been both warned and encouraged to eat the very same food stuffs. And, depending on how the authors view the focus of their articles, scientific studies have appeared in both, journals dealing with nutrition as well as journals on oncology. A journal dedicated to the interplay of dietary habits, food, nutrients, metabolism and cancer was, however, has been previously non-existent. A better understanding of how single nutrients react, both in an isolated state, as well as in combination with other complex substances, has been made possible over the course of the past few years and decades thanks to new develpments in technology and the ensuing discoveries. Likewise singular nutrients have been shown to display both positive and negative effects on the development of neoplastic cells as well as interacting with cancer therapies. A classic example of this is the discussion concerning the pros and cons of antioxidants. By focussing on metabolic proc- esses in cancer, MNO aims to encourage researchers to study the relationship between tumor metabolism and food products and their respective constituents.

Another example for the effect nutrition can effect on cancer cells is the ketogenic diet, which has often been proposed as a therapeutic measure over the past years. There is a growing amount of evidence that justifies a critical examination of the effectiveness and impact of ketogenic diets and their influence on tumor metabolism, opening up new and interesting avenues for research in oncology. The relationship between nutrition and metabolism is becomes even more significant when considering the fact that tumor patients are usually found to be malnourished. In this context, new insights into the relationship between microbiomes and malnutrition could open up new horizons in improving the nutritional status of cancer patients. A journal that takes nutrition, food and its elements into account when examining oncological issues allows readers with a primarily oncology-based background to discover new possibilities of nutrition as part of the prevention and treatment of cancer. At the same time, there are new impulses to be had for researchers specialising in biochemistry, nutrition science, endocrinology and related fields. And that is exactly why a new journal such as this one is needed. 